Article

\title{
Revalorization of Pleurotus djamor Fungus Culture: Fungus-Derived Carbons for Supercapacitor Application
}

\author{
Paola Navid García-Hernández, José Martín Baas-López, Tanit Toledano-Thompson, Ruby Valdez-Ojeda *[D \\ and Daniella Pacheco-Catalán *(D)
}

check for updates

Citation: García-Hernández, P.N.; Baas-López, J.M.;

Toledano-Thompson, T.;

Valdez-Ojeda, R.; Pacheco-Catalán, D.

Revalorization of Pleurotus djamor

Fungus Culture: Fungus-Derived

Carbons for Supercapacitor

Application. Sustainability 2021, 13,

10765. https://doi.org/10.3390/

su131910765

Academic Editor: Farooq Sher

Received: 3 August 2021

Accepted: 22 September 2021

Published: 28 September 2021

Publisher's Note: MDPI stays neutral with regard to jurisdictional claims in published maps and institutional affiliations.

Copyright: (c) 2021 by the authors. Licensee MDPI, Basel, Switzerland. This article is an open access article distributed under the terms and conditions of the Creative Commons Attribution (CC BY) license (https:// creativecommons.org/licenses/by/ $4.0 /)$.
Unidad de Energía Renovable, Centro de Investigación Científica de Yucatán, Parque Científico Tecnológico de Yucatán, Carretera Sierra Papacal-Chuburná Puerto, Km5, Mérida 97302, Mexico; paola.garcia@cicy.mx (P.N.G.-H.); jose.baas@cicy.mx (J.M.B.-L.); tanit@cicy.mx (T.T.-T.)

* Correspondence: ruby.valdez@cicy.mx (R.V.-O.); dpacheco@cicy.mx (D.P.-C.); Tel.: +52-999-93889-83-30 (D.P.-C.); Fax: +52-999-981-39-00 (D.P.-C.)

Abstract: Currently, there is increasing interest and effort directed to developing sustainable processes, including in waste management and energy production and storage, among others. In this research, corn cobs were used as a substrate for the cultivation of Pleurotus djamor, a suitable feedstock for the management of these agricultural residues. Revalorization of this fungus, as an environmentally friendly carbon precursor, was executed by taking advantage of the intrinsic characteristics of the fungus, such as its porosity. Obtaining fungus-derived porous carbons was achieved by hydrothermal activation with $\mathrm{KOH}$ and subsequent pyrolysis at 600,800 , and $1000{ }^{\circ} \mathrm{C}$ in an argon atmosphere. The morphologies of the fungal biomass and fungus-derived carbons both exhibited, on their surfaces, certain amorphous similarities in their pores, indicating that the porous base matrix of the fungus was maintained despite carbonization. From all fungus-derived carbons, PD1000 exhibited the largest superficial area, with $612 \mathrm{~m}^{2} \mathrm{~g}^{-1}$ and a pore size between 3 and $4 \mathrm{~nm}$ recorded. Electrochemical performance was evaluated in a three-electrode cell, and capacitance was calculated by cyclic voltammetry; a capacitance of $60 \mathrm{~F} \mathrm{~g}^{-1}$ for PD1000 was recorded. Other results suggested that PD1000 had a fast ion-diffusion transfer rate and high electronic conductivity. Ultimately, Pleurotus djamor biomass is a suitable feedstock for obtaining carbon in a sustainable way, and it features a defined intrinsic structure for potential energy storage applications, such as electrodes in supercapacitors.

Keywords: Pleurotus djamor; energy storage; supercapacitors; revalorization

\section{Introduction}

In recent years, the use of renewable and sustainable generation systems has continued to grow. However, they have intermittent properties, and thus significantly depend on energy storage systems. In parallel, the fast-growing demand for portable electronic devices and electric vehicles has increased the advancement of science and technology related to energy storage [1].

In this sense, electric double-layer capacitors, or supercapacitors, have attracted attention due to their high power density $\left(>10 \mathrm{kWkg}^{-1}\right)$, fast charge/discharge cycles (within seconds), extremely long cyclic life (>105 cycles), high efficiency ( $>90 \%)$, low maintenance costs, etc. [2,3]. Supercapacitors contain four main parts: the electrodes, binder, electrolyte, and membrane. All these components have been investigated with the aim of improving the electrochemical performance of supercapacitors. Electrodes have the largest influence on the performance of the supercapacitors; thus, they are the most important component. Consequently, the research and development of high-performance electrode materials are of great importance. Preparing electrode materials in an efficient and environmental way involves the use of renewable resources [1]. 
Carbon is the main electrode material used, chosen for both its high electrostatic capacity and its cyclical stability; however, in commercial supercapacitors, their materials rely on fossil-fuel-based precursors [4]. Therefore, carbon derived from biomass has been suggested as an ideal electrode material for sustainable development due to its intrinsic benefits, such as a porous structure that facilities the accessibility and diffusion of electrolyte ions through micropores and mesopores interconnected within the material, resulting in a greater surface area and capacitance $[5,6]$. The electrochemical properties of these carbonderived biomass materials are largely dependent on the raw materials and the method of preparation [7].

Fungi exhibit rapid growth rates through a wide variety of forestall and agricultural residues, with well-known negative impacts on the environment, as well as on human and animal health [8]. Additionally, fungi possess cell walls rich in chitin, whose hydroxyl groups prevent agglomeration under heat treatments during the in situ synthesis of complex metals $[2,9,10]$. Another advantage is that their nitrogen content $(3-10 \%)$ [11] contributes to the obtaining of nitrogen-doped biomass-derived carbons [5]. In 2006, Mexico produced 75.73 million tons of agricultural residues, which could be potentially used for the cultivation of fungi, contributing to the recycling of agro-industrial residues [12] and providing added value and better management.

To date, there are few works related to the application of fungi for energy storage. Long et al. [2] used dry Auricularia sp. to synthesize densely porous graphene-type carbon, using different methods to obtain active carbon, and then employed them as electrodes to fabricate supercapacitors, whose electrochemical properties were evaluated. They reported that the $\mathrm{KOH}$ activation of the carbon derived from Auricularia increased the surface area to $1103 \mathrm{~m}^{2} \mathrm{~g}^{-1}$, with a specific capacitance of $374 \mathrm{~F} \mathrm{~g}^{-1}$ in the $6 \mathrm{M} \mathrm{KOH}$ recorded.

Zhu et al. [10] synthesized nanohybrid graphene incorporated into carbon derived from Auricularia sp. The procedure used resulted in a balanced number of meso- and micropores, with a specific surface area of $1723 \mathrm{~m}^{2} \mathrm{~g}^{-1}$ and a specific capacitance of $256 \mathrm{~F} \mathrm{~g}^{-1}$ at $1 \mathrm{~A} \mathrm{~g}^{-1}$ recorded.

Zheng et al. [4] synthesized 3D porous carbon using dictyophora as biomass, using hydrothermal carbonization with $\mathrm{KOH}$ at different concentrations at $120^{\circ} \mathrm{C}$; subsequently, the material obtained was pyrolyzed at $650{ }^{\circ} \mathrm{C}$ under an $\mathrm{N}^{2}$ atmosphere. The resulting material presented a high specific capacitance of $310 \mathrm{~F} \mathrm{~g}^{-1}$ in a $6 \mathrm{M} \mathrm{KOH}$ electrolyte. This research has shown promising results for the use of this material as an electrode in electrochemical capacitors.

Particularly, Pleurotus djamor (PD) is a native fungus that is commercially cultivated in diverse regions around the world and has the ability to grow quickly in warm temperatures [13]. Additionally, Pleurotus djamor has cultivation cycles that are shorter than those of other commercial species in the genus [11].

Thus, in this study, Pleurotus djamor (PD) was employed as a precursor biomass to obtain porous carbons without templates, using the intrinsic porous structure of the mushroom through a hydrothermal activation process with $\mathrm{KOH}$ and one-step pyrolysis at different temperatures. Through this method, the carbon content of the initial feedstock can be increased, the macrocellular structure of the biomass is stabilized, a higher mesoporosity is provided, most of the volatile oxygenated compounds are eliminated, and the formation of ash is reduced [14-16]. Being a method that does not use organic solvents, catalysts or surfactants it is considered "green" [17].

\section{Materials and Methods}

\subsection{Fungus Culture}

The mother culture of the P. djamor strain (ECS-0142) was obtained from El Colegio De La Frontera Sur (ECOSUR, Chiapas, México) using the process described by Guzmán [18]. Aseptically, $1 \mathrm{~cm}^{2}$ of mycelium from the mother culture was inoculated in a medium composed of malt extract $\left(12 \mathrm{~g} \mathrm{~L}^{-1}, \mathrm{BD}_{\text {Bacto }}^{\mathrm{TM}}\right)$, dextrose $\left(10 \mathrm{~g} \mathrm{~L}^{-1}\right.$, Fermont $\left.{ }^{\mathrm{TM}}\right)$, peptone $\left(1 \mathrm{~g} \mathrm{~L}^{-1}, \mathrm{MCD} \mathrm{LAB}^{\mathrm{TM}}\right)$, and bacteriologic agar $\left(18 \mathrm{~g} \mathrm{~L}^{-1}, \mathrm{BD}\right.$ Bioxon $\left.{ }^{\mathrm{TM}}\right)$. Then, the mixture 
was incubated at $20-28{ }^{\circ} \mathrm{C}$ for 15 days. As the initial substrate, we used forage sorghum, which was previously sterilized and hydrated to $60 \%-65 \%$ humidity. This substrate was used to inoculate $1 \mathrm{~cm}^{2}$ fragments of mycelium, and this was maintained in the dark at $20-28{ }^{\circ} \mathrm{C}$ for 30 days. Once the mycelium completely covered the initial substrate, $50 \mathrm{~g}$ of the initial substrate was mixed with $1 \mathrm{Kg}$ of maize cobs (cultivation substrate) previously hydrated for $12 \mathrm{~h}$ to $3 \%-5 \%$ humidity and sterilized. The mixture was then placed in $30 \mathrm{~cm} \times 50 \mathrm{~cm}$ polypropylene bags, which were sealed and incubated in the dark at $20-28{ }^{\circ} \mathrm{C}$ in a culture room with a relative humidity of $80 \%$ for 20 days. After this time, cuts were made on the polypropylene bags without cutting the cultivation substrate; these were placed under illumination by a cool white color for $12 \mathrm{~h}$ a day for 30 days with a relative humidity of $80 \%-90 \%$, and with the same temperature. Fruiting bodies $5-10 \mathrm{~cm}$ in diameter were collected 4 times for the substrate.

\subsection{Fungus Activation}

Fresh $P$. djamor mushrooms were washed with deionized water to remove impurities and dried in an oven at $70{ }^{\circ} \mathrm{C}$ for $4 \mathrm{~h}$. Chemical activation was conducted hydrothermally: $1.2 \mathrm{~g}$ of dried mushrooms and $80 \mathrm{~mL}$ of $0.5 \mathrm{M} \mathrm{KOH}$ (Sigma-Aldrich ${ }^{\mathrm{TM}}$ ) were added into a 100-mL Teflon-lined stainless autoclave. The hydrothermal reaction was induced at $120{ }^{\circ} \mathrm{C}$ for $6 \mathrm{~h}$, and then the material was allowed to cool at an ambient temperature. This resulting material was named $\mathrm{PDH}$. The obtained material was washed with deionized water, frozen for $48 \mathrm{~h}$ and then freeze-dried ( $\mathrm{LABCONCO}^{\mathrm{TM}}$ ) for another $48 \mathrm{~h}$. This material was named PDL.

\subsection{Pyrolysis Experiment}

Pyrolysis was carried out in a tube furnace (Lindberg Blue M Thermo Scientific ${ }^{\mathrm{TM}}$ ) under an argon atmosphere at a heating rate of $5^{\circ} \mathrm{C} \min ^{-1}$ for $2 \mathrm{~h}$ at 600,800 , and $1000{ }^{\circ} \mathrm{C}$, respectively. The obtained fungus-derived carbons were washed with $10 \% \mathrm{HCl}$ (Fermont ${ }^{\mathrm{TM}}$ ) and deionized water and then dried at $80^{\circ} \mathrm{C}$ for $12 \mathrm{~h}$. The resulting material was identified as PDx, where $x$ is the pyrolysis temperature used $(x=600,800$, or 1000). Figure 1 illustrates the processes for obtaining fungus-derived carbons.
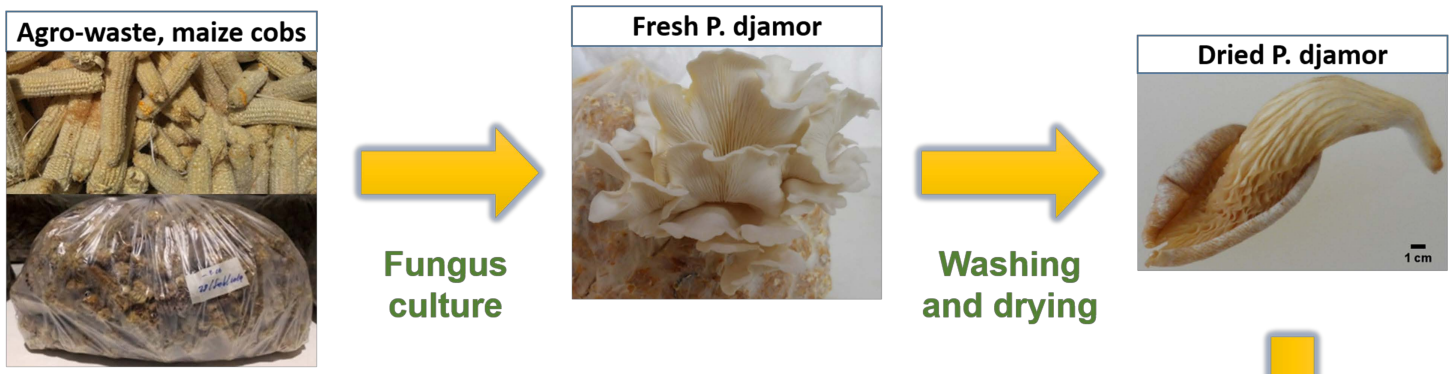

culture and drying

\section{Hydrothermal} $0.5 \mathrm{M} \mathrm{KOH}$
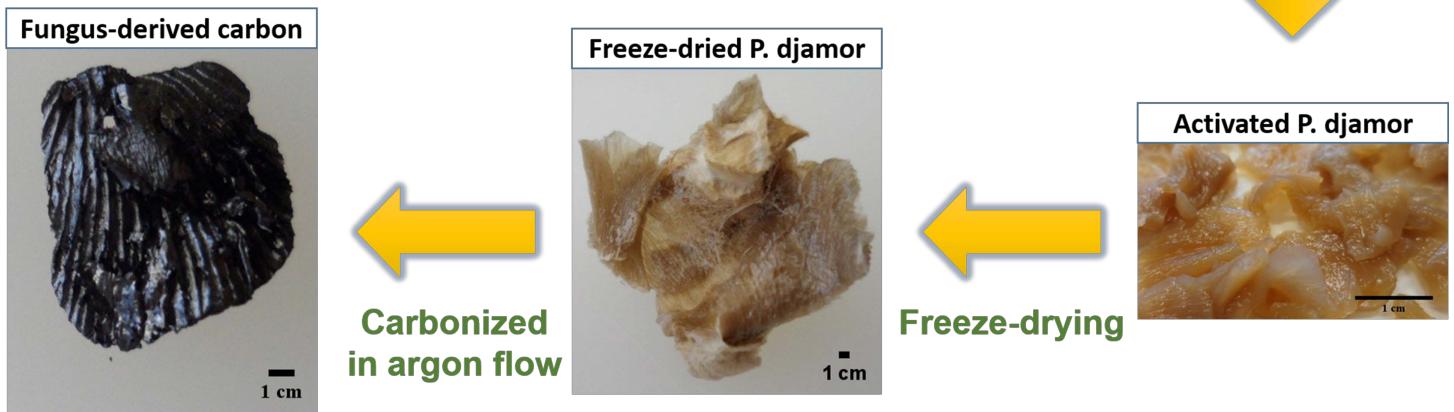

Figure 1. Scheme for obtaining fungus-derived carbons. 


\subsection{Analysis of Fungus-Derived Carbons}

\subsubsection{Morphological Analysis}

Scanning electron microscopy images were obtained using a JEOL, JSM-6360 LV-Y1. The high-resolution transmission electron microscopy (HRTEM) images were taken by a JEOL JEM-2010 electron microscope (JEOL Ltd. ${ }^{\mathrm{TM}}$ ) operating at $200 \mathrm{kV}$.

\subsubsection{Physicochemical Characterization}

Power X-ray diffraction was performed using a D2 PHASER Bruker. The XRD diffraction patterns were obtained at room temperature using a monochromatic $\mathrm{Cu} K \alpha$ radiation source $(\lambda=0.154 \mathrm{~nm})$ at a scan rate of $5^{\circ}$ per minute from $10^{\circ}$ to $80^{\circ}$. The interlayer spacing $\left(d_{002}\right)$ was calculated using Bragg's law $[19,20]$ :

$$
d_{002}=n \lambda /\left(2 \sin \theta_{002}\right)
$$

where $n$ is an integer whose order of reflection is normally assumed to be equal to $1, \lambda$ is the wavelength of the $X$-ray, and $\theta_{002}$ is the angle between the incident beam and the lattice planes in degrees.

The average crystallite size was determined using Scherrer equations [19,21]:

$$
\begin{aligned}
& L a=1.84 \lambda /\left(\beta_{100} \cos \theta_{100}\right) \\
& L c=0.89 \lambda /\left(\beta_{002} \cos \theta_{002}\right)
\end{aligned}
$$

where $L a$ and $L c$ are the lateral size and stacking height of the crystallite, respectively; $\beta_{100}$ and $\beta_{002}$ are the full widths at half-maximum (FWHM) of the (100) and (002) peaks in the radians, respectively; $\theta$ is the corresponding scattering angles in radians.

Raman spectra were collected on a Thermo Scientific DXR Raman microscope using a $633 \mathrm{~nm}$ laser. The chemical composition was resolved by X-ray photoelectron spectroscopy (XPS) with a 5600 ESCA/SAM system (Perkin Elmer ${ }^{\mathrm{TM}}$ ) using monochromatized $\mathrm{Al} \mathrm{K} \alpha$ radiation $(1486.6 \mathrm{eV})$. The surface area was determined by the Brunauer-Emmett-Teller (BET) method. The composition of the surface elements was recorded in a Perkin-Elmer model 5600 ESCA/SAM equipped with a double-pass cylindrical mirror analyzer, using a monochromatic source for AL K $\alpha(1486.6 \mathrm{eV})$.

\subsubsection{Elemental Analysis}

Elemental analysis was performed in duplicate using a Thermo Scientific Elemental Analyzer Flash 2000. Nitrogen adsorption-desorption isotherms were collected at $-196^{\circ} \mathrm{C}$ using a NOVAtouch Quantachrome ${ }^{\mathrm{TM}}$ instrument. Before measurements, the fungusderived carbons were degassed under a vacuum. For the hierarchical porous carbon, this process was performed at $200^{\circ} \mathrm{C}$ for $6 \mathrm{~h}$, while for the dried fungus, $60^{\circ} \mathrm{C}$ for $6 \mathrm{~h}$ was used.

\subsubsection{Electrochemical Measurement in a Three-Electrode System}

All electrochemical measurements were carried out using a multi-channel potentiostat VMP3B-10 (BioLogic Science Instruments ${ }^{\mathrm{TM}}$ ) in the Electrochemical laboratory of the Renewable Energy Unit (CICY). The electrochemical performance of the fungus-derived carbons was measured in a standard three-electrode system with a graphite rod as the counter electrode, a saturated calomel $\mathrm{Hg} / \mathrm{HCl}_{2}$ (SCE) electrode as the reference electrode, the fungus-derived carbon as the working electrode, and $6 \mathrm{M} \mathrm{KOH}$ aqueous solution as the electrolyte. Preparation of the electrodes was performed as follows: $60 \mathrm{wt} \%$ fungus-derived carbon sample, $30 \mathrm{wt} \%$ super P carbon black, and $10 \mathrm{wt} \%$ polytetrafluoroethylene (PFTE) binder mixed in ethanol. The resulting slurry was dried at $80^{\circ} \mathrm{C}$ for $15 \mathrm{~min}$ and then pasted on a stainless-steel sheet $\left(1 \mathrm{~cm}^{2}\right)$ and pressed at $14 \mathrm{MPa}$ with a mass loading of about $10.0 \mathrm{mg} \mathrm{cm}^{-2}$. Finally, the working electrode was soaked in $6 \mathrm{M} \mathrm{KOH}$ for $12 \mathrm{~h}$. Cyclic voltammetry $(\mathrm{CV})$ experiments were carried out between 0 and $-0.5 \mathrm{~V}$ for PD600, from -0.1 to $-0.6 \mathrm{~V}$ for PD800, and from 0 to $-0.7 \mathrm{~V}$ for PD1000, at a scan rate of $5 \mathrm{mVs}^{-1}$. The 
electrochemical impedance spectroscopy (EIS) measurements were performed under open circuit potential over a frequency range of $100 \mathrm{kHz}$ to $10 \mathrm{mHz}$ with an amplitude of $10 \mathrm{mV}$.

The specific capacitance $\left(C_{s p}\right)$ of the electrodes was calculated from the CV curves using the following equation [22]:

$$
C_{s p}=Q /((\Delta V)(\delta v / \delta t)(m))
$$

where $Q$ is the area under the $C V$ curve, $\Delta V$ is the potential window, $\partial v / \partial t$ is the scan rate, and $m$ is the mass of the active material.

\section{Results and Discussion}

\subsection{Fungus Culture}

Mycelium from the mother culture of $P$. djamor covered all areas of the Petri dish by the 15th day of cultivation. Then, on the 30th day, forage sorghum was employed for dense mycelium propagation. After further inoculating the forage sorghum with cobs, the newly produced "cakes" were perforated for oxygenation on the 15th day of inoculation. After the mycelium covered the entire substrate, the first fungal body of P. djamor (white variety) emerged on the 30th day of cultivation. After one week, the primordia matured to adulthood. The rest of the fruiting bodies or carpophores emerged within the period of 30 to 60 days of culture (Figure 2). Harvest was realized using a sterile knife. Occasionally, we observed turgid caps in the larger carpophores. In the literature, cultivation periods similar to those obtained in this research have been reported, using other agricultural residues such as rice straw, sorghum straw, and sugarcane bagasse [23,24].

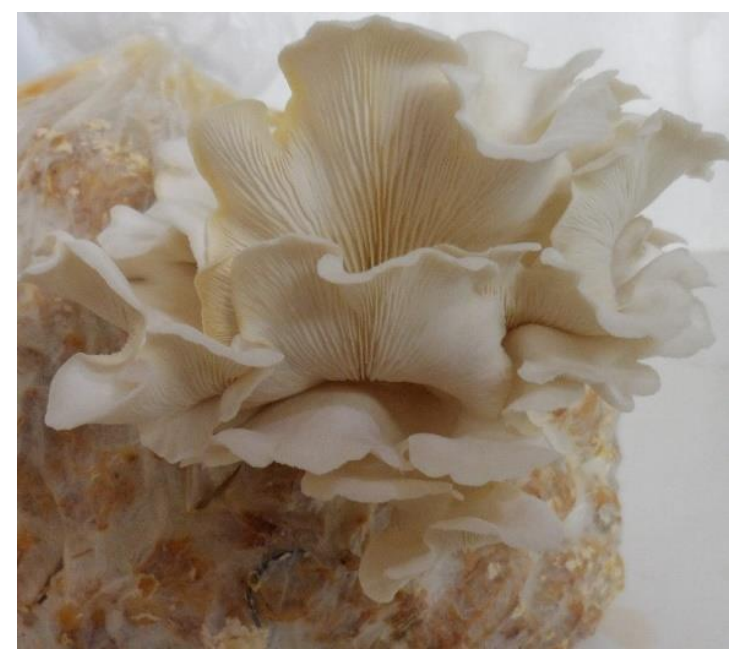

Figure 2. P. djamor bodies or carpophores after the 60th day of cultivation.

\subsection{Chemical Structure of Fungus}

The spectrum of fresh P. djamor (Figure 3) showed peaks at $3295 \mathrm{~cm}^{-1}$, corresponding to $\mathrm{OH}$ and $\mathrm{NH}$; at 2919 and $2855 \mathrm{~cm}^{-1}$ due to the stretching vibration of the $\mathrm{CH}$ bond; at $1546 \mathrm{~cm}^{-1}$ due to the deformation of the bond $\mathrm{N}-\mathrm{H}$; at band $1414 \mathrm{~cm}^{-1}$, corresponding to a symmetric deformation of the $\mathrm{CH}_{3}$ group; the stretching of the $\mathrm{C}-\mathrm{C}$ bond at $1154 \mathrm{~cm}^{-1}$; the stretching of the $\mathrm{C}-\mathrm{O}, \mathrm{C}-\mathrm{H}$, and $\mathrm{NH}$ bonds at 1034,893 , and $693 \mathrm{~cm}^{-1}$, respectively; and the signals obtained correspond to the structure present in chitin $[25,26]$. The high nitrogen content in the chitin structure makes it possible to obtain carbonaceous material doped with nitrogen through a pyrolysis process without an additional nitrogen doping agent [27]. The spectrum obtained is similar to obtained for other species of the same genus of fungus, such as P. eryngii and P. ostreatus [28]. 


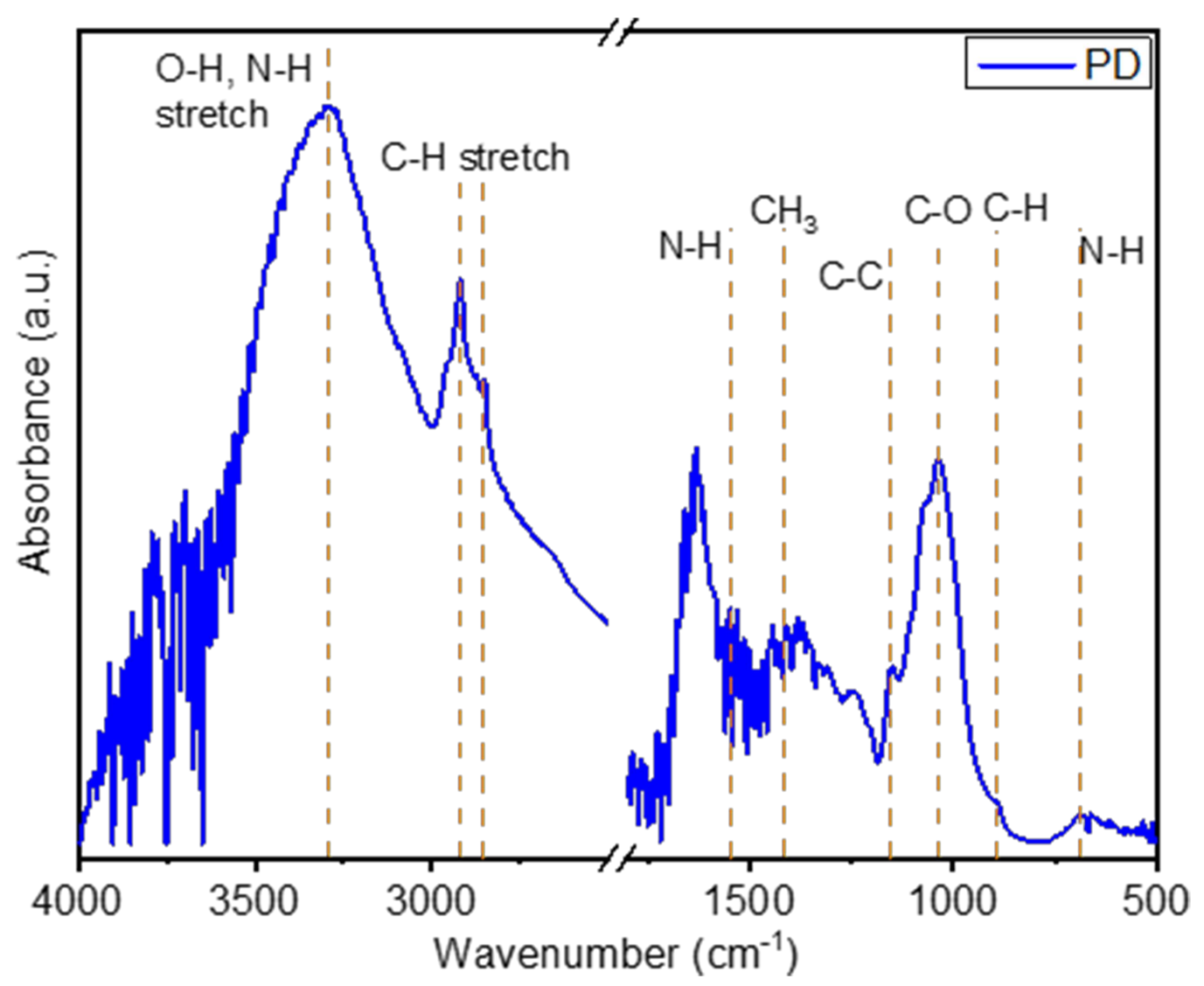

Figure 3. FTIR spectra of P. djamor.

\subsection{Analysis of the Porous Structure}

The porous structure of the fungus, illustrated through SEM, indicated evident morphological changes during the activation process of the fungus. PD showed an internal network-type morphology (Figure 4a). After $\mathrm{KOH}$ activation ( $\mathrm{PDH}$, Figure $4 \mathrm{~b}$ ), the fungal structure was visibly rougher and more compact on its surface compared to the untreated fungus. After freeze-drying, the fungus showed an almost-smooth surface with divisions in the structure (PDL, Figure 4c). The porosities of the fungus-derived carbons of PD600 (Figure 4d), PD800 (Figure 4e), and PD1000 (Figure 4f) were similar to that of PD (Figure 4a). In all carbons, we observed innumerable pores on their surfaces, indicating that the PD was highly porous. From the SEM image, one can observe micro- and mesopores, with average diameters of 4 to $7 \mu \mathrm{m}$ for PD600, PD800, and PD1000, regularly arranged on the surface. The cavities evolved in the macropores and micropores in PD600, PD800, and PD1000, which interconnected through some smaller pores embedded in the macropores walls. At a lower pyrolysis temperature, the porous structure became more defined, since the increase in temperature caused sections of the pores to collapse. In PD1000, one can observe carbon monoliths exhibiting nearly smooth exterior layers. However, the internal part had interconnected pores, which was observed when the monoliths broke up. The SEM micrographs also confirmed greater pore formation by the use of the hydrothermal method and $\mathrm{KOH}$ for their activation [2].

Meanwhile, through TEM (Figure 5a-f), we observed interconnected micro- and mesopores in the fungus-derived carbons, resulting in carbon with a hierarchical porous structure. This structure can provide more active sites for electrochemical reactions and facilitate the movement of ions through the material [2]. Notably, while interconnections were evident between the macro-, meso-, and micropores in PD800 (Figure 5c,d) and PD1000 (Figure 5c,d), in PD600 (Figure 5e,f), micropores with compact structures predominated. In another investigation carried out using the Auricularia fungus [2], they obtained similar results in the morphology of the carbon, with the presence of micropores, 
macropores, and mesopores. This is thanks to the set of hydrothermal activation and pyrolysis procedures. The SEM and TEM characterizations demonstrated that macro- and mesopores interconnected in PD800 and PD1000, forming a carbon with a hierarchically porous structure.

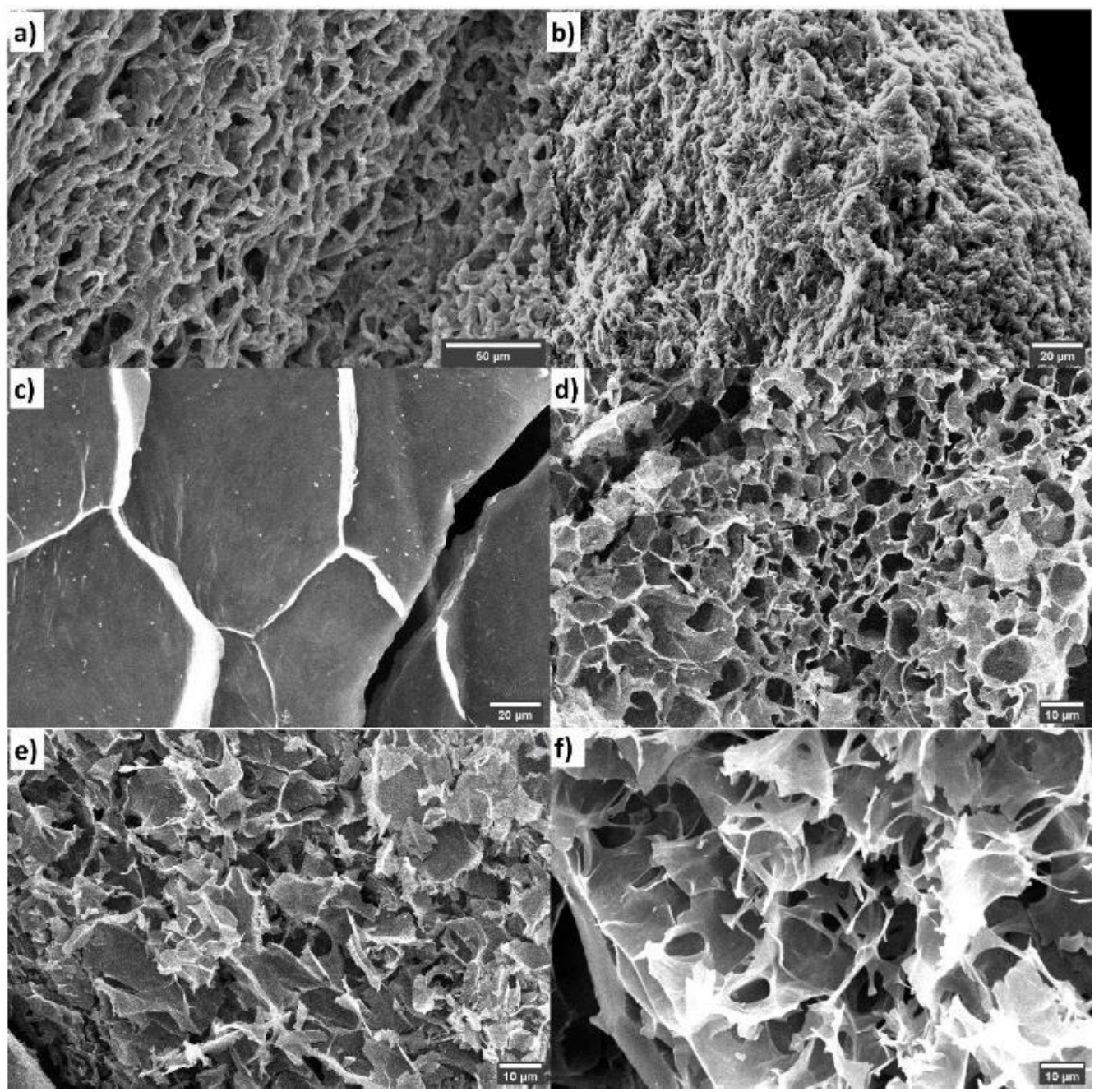

Figure 4. SEM images of (a) PD; (b) PDH; (c) PDL; (d) PD600; (e) PD800; (f) PD1000.

$\mathrm{N}_{2}$ adsorption-desorption tests were carried out to better understand the porous structure. PD (Figure 6a) showed a type IV isotherm due to the presence of mesopores in the biomass [29]. However, the density functional model (DFT) employed to calculate the pore size distribution indicated that PD featured a greater distribution of micropores than mesopores (Figure 6b; Table 1).

The isotherms of fungus-derived carbons (Figure 6a) in PD800 and PD1000 suggested combined behavior of type I and type IV isotherms (according to IUPAC), indicating an increase in adsorption at low relative pressures due to the presence of micropores. We also observed a type $\mathrm{H} 4$ weak hysteresis loop at high relative pressures above 0.5 , which was attributed to capillary condensation in the mesopores. PD600 was found to be similar to a type II isotherm due its mesopores and the presence of macropores [27,29-31]. The pore size distribution calculated using the density functional theory model (DFT) (Figure 6b) indicated that PD800 and PD1000 had a similar pore distribution of 0.5-2 nm with a low participation of mesopores, unlike PD600, in which mesopores predominated. 


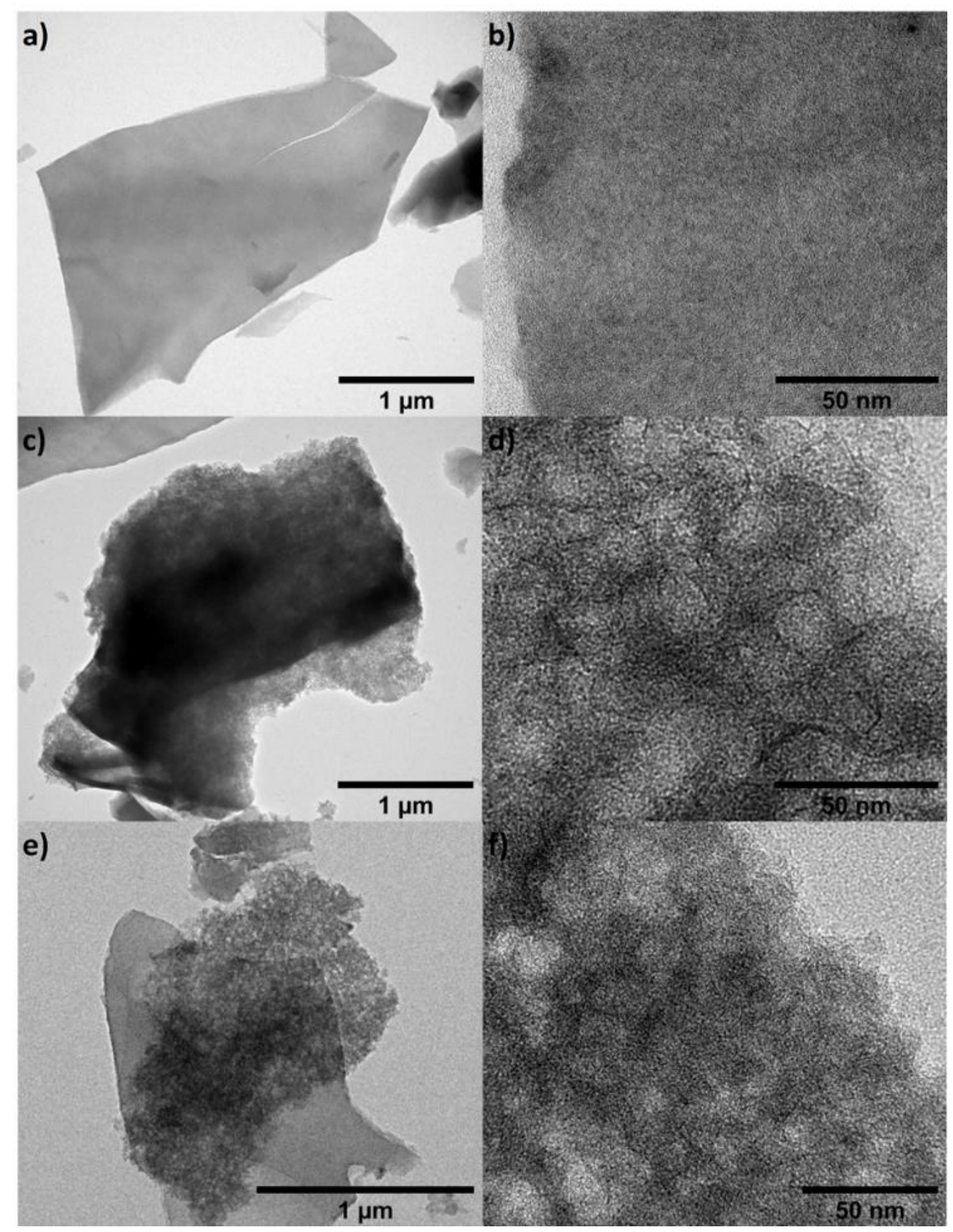

Figure 5. High-resolution TEM (HRTEM): (a) PD600, (c) PD800, and (e) PD1000. More magnified images are provided in $(\mathbf{b}, \mathbf{d}, \mathbf{f})$ for each of the carbons. 

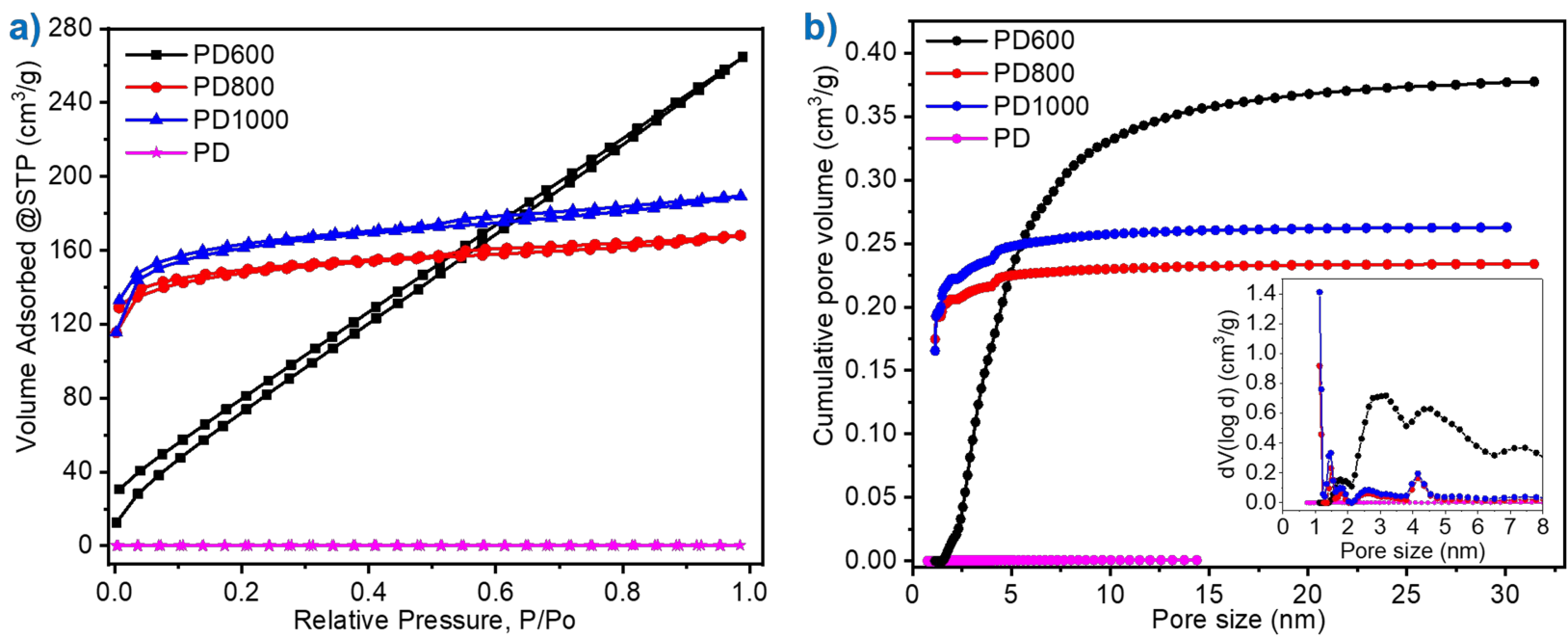

Figure 6. (a) $\mathrm{N}_{2}$ adsorption-desorption isotherms; (b) pore size distribution curves of the fungus.

Table 1. Porosity data and elemental analysis of fungus-derived carbons.

\begin{tabular}{|c|c|c|c|c|c|c|c|}
\hline \multirow[b]{2}{*}{ Samples } & \multicolumn{3}{|c|}{ Porosity } & \multicolumn{4}{|c|}{ Elemental Analysis (wt\%) } \\
\hline & $\begin{array}{c}S_{\text {BET }}{ }^{a} \\
\left(\mathrm{~m}^{2} \cdot \mathrm{g}^{-1}\right)\end{array}$ & $\begin{array}{l}V_{\text {Toltal }} b \\
\left(\mathrm{cc} \cdot \mathrm{g}^{-1}\right)\end{array}$ & ${\underset{\text { Average }}{\text { (nm) }}}^{\mathrm{D}^{\mathrm{c}}}$ & $\mathrm{C}$ & $\mathbf{H}$ & $\mathbf{N}$ & $O^{d}$ \\
\hline PD & 0.25 & 0.00 & 3.19 & 46.77 & 5.53 & 5.38 & 42.32 \\
\hline PD600 & 361.22 & 0.33 & 3.18 & 78.19 & 1.55 & 4.07 & 16.19 \\
\hline PD800 & 563.52 & 0.03 & 4.36 & 83.11 & 0.90 & 1.81 & 14.18 \\
\hline PD1000 & 612.45 & 0.05 & 4.36 & 79.55 & 0.75 & 1.02 & 18.68 \\
\hline
\end{tabular}

a Total surface area calculated using the BET method. ${ }^{\mathrm{b}}$ Total pore volume calculated at $\mathrm{P} / \mathrm{P} 0=0.99 .{ }^{\mathrm{c}}$ Average pore diameter calculated from $\mathrm{BJH}$ desorption. ${ }^{\mathrm{d}}$ From calculated values.

In PD600, we observed micropores formed by the low temperature used. This porous structure, which arises in all fungus-derived carbon, enables the electrolyte to penetrate into the bulk particles to form three-dimensional channels for ion transport [32], which is very beneficial for electrochemical performance. The rich macro- and mesopores in PD800 and PD1000 could be attributed to the special texture of PD, in which many water molecules and bio-macromolecules are present. When these molecules are removed during the activation process, cavities are produced, which ultimately evolve into mesopores. Micropores arise from activated reactions between carbon atoms and $\mathrm{KOH}$ at high temperatures $(6 \mathrm{KOH}+2$ $\mathrm{C}=2 \mathrm{~K}+3 \mathrm{H}_{2}+2 \mathrm{~K}_{2} \mathrm{CO}_{3}$ ) [33]. This assumption was supported by the porous structure analysis of $\mathrm{PD}, \mathrm{PDH}$, and $\mathrm{PDL}$, in which micropores were found to be scarce compared to PD600, where micropores were evident.

These results contrast somewhat with those obtained from the $\mathrm{N}_{2}$ adsorption-desorption test, because the SEM and TEM images illustrated the predominance of macropores based on increasing temperatures due to limitations of distinguishability. This factor was clarified by the $\mathrm{N}_{2}$ adsorption-desorption test. Countless micro- and mesopores within each sample, particularly in PD800 and PD1000, were not visible in the SEM/TEM-derived micropores, resulting in a highly porous structure among the samples. Specifically, the rich microand mesopores could be attributed to the special fungal structure of PD, similar to that in wild jujube pit [32]. Notably, micropores provide cavities for electrolyte ions to be absorbed, while meso- and macropores facilitate faster electron ion transport by minimizing molecular diffusion limitations [34], thereby enhancing the electrochemical double-layered capacitance of the porous carbon materials.

The BET surface area and pore parameters (Table 1) indicated that PD1000 had the largest surface area $\left(612.45 \mathrm{~m}^{2} \mathrm{~g}^{-1}\right)$ compared to the other two carbons, and an average pore diameter of 3 to $4 \mathrm{~nm}$. The low surface area of PD compared to that of the fungus-derived carbons indicated that the hydrothermal activation process with $\mathrm{KOH}$ promoted an increase 
in surface area. We also observed increases in the pyrolysis temperature and surface area. The total BET surface area of PD increased in PD600, PD800, and PD1000. The surface areas from other sources, such as Auricularia sp. $\left(80 \mathrm{~m}^{2} \mathrm{~g}^{-1}\right.$ [9] and $\left.1103 \mathrm{~m}^{2} \mathrm{~g}^{-1}\right)$ [2], seaweed $\left(746 \mathrm{~m}^{2} \mathrm{~g}^{-1}\right)$ [35], Lessonia nigrescens $\left(746 \mathrm{~m}^{2} \mathrm{~g}^{-1}\right)$ [36], Ganoderma lacidum $\left(430 \mathrm{~m}^{2} \mathrm{~g}^{-1}\right)$ [37], and Calocybe indica $\left(958 \mathrm{~m}^{2} \mathrm{~g}^{-1}\right)$ [37] were close to-and in some cases, lower than-the surface areas of most active carbons $\left(>1000 \mathrm{~m}^{2} \mathrm{~g}^{-1}\right)$. It was previously anticipated that such an enlargement might further enhance electrochemical capacitance [9].

Elemental analysis indicated that the percentage of $\mathrm{C}$ in PD was similar to that reported for other biomass sources employed for carbon synthesis, such as rice straw (38.52\%), wheat straw (42.11\%), and corn (44.53\%) [38], which is within the adequate parameter to have a good performance as a carbon precursor. On the other hand, the percentage of $\mathrm{N}$ present in the fungus-derived carbons was low and diminished as pyrolysis temperature increased.

\subsection{Crystal Structure Analysis}

All the XRD diffraction patterns of the fungus-derived carbons (Figure 7a) exhibited two broad peaks centered around $23^{\circ}$ and $44^{\circ}$, corresponding to the diffraction planes $((002)$ and (100), respectively) of the graphite structure. All fungus-derived carbons exhibited weak and broad diffraction peaks, suggesting that they were amorphous carbons. As pyrolysis temperature increased, the peak at $44^{\circ}$ became more visible due to an increase in the degree of graphitization $[30,39]$.
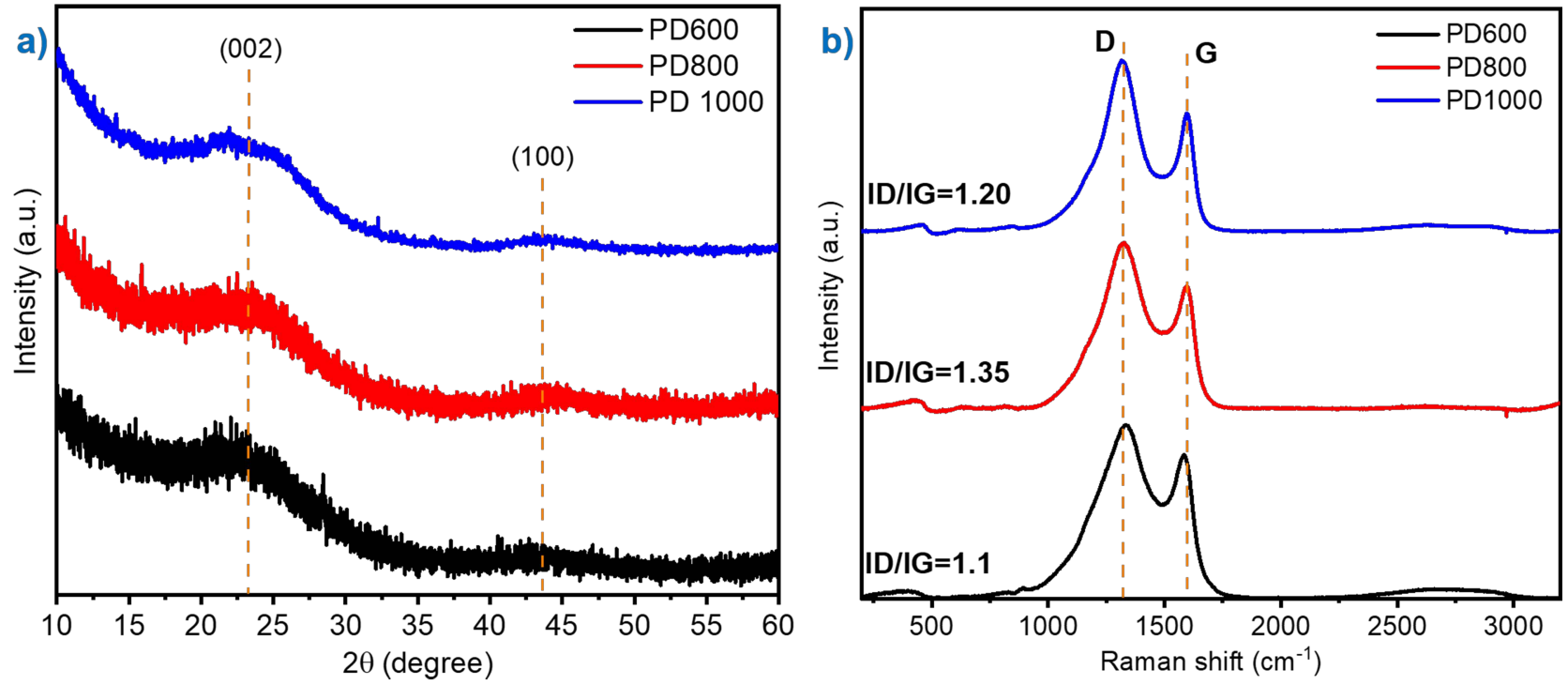

Figure 7. (a) XRD patterns; (b) Raman spectra of fungus-derived carbons.

Table 2 summarizes the values of the interlayer spacing $\mathrm{d}_{002}$, the stack thickness $L_{\mathcal{C}}$, and the lateral size of stack $L_{a}$, calculated by Equations (1)-(3), respectively. The distance $d_{002}$ was greater than that of graphite $(\sim 0.335 \mathrm{~nm})$ in all cases, due to the defects caused by activation with $\mathrm{KOH}$. The amorphous carbon we obtained was consistent with the fungus-derived carbon of Pleurotus eryngii [40], Dictyophora sp. [4], Agaricus sp. [33], and Tyromyces fissilis [41]. The latter showed similar values for interlayer distance $(\sim 0.386 \mathrm{~nm})$ to those obtained in the present study.

Table 2. Structural parameters in fungus-derived carbons calculated from XRD analysis.

\begin{tabular}{cccc}
\hline Sample & $\boldsymbol{d}_{\mathbf{0 0 2}}(\mathbf{n m})$ & $\boldsymbol{L}_{\boldsymbol{a}}(\mathbf{n m})$ & $\boldsymbol{L}_{\boldsymbol{c}}(\mathbf{n m})$ \\
\hline PD600 & 0.386 & 3.677 & 0.897 \\
PD800 & 0.391 & 2.697 & 1.025 \\
PD1000 & 0.376 & 2.761 & 1.053 \\
\hline
\end{tabular}


The Raman spectra (Figure $7 \mathrm{~b}$ ) showed two broad peaks located at approximately $1325 \mathrm{~cm}^{-1}$ and $1592 \mathrm{~cm}^{-1}$ for PD800 and PD1000 and at $1334 \mathrm{~cm}^{-1}$ and $1582 \mathrm{~cm}^{-1}$ in PD600, corresponding, respectively, to bands D and G. The D band relates to disorder in the carbon structure due to either structural defects or impurities, and the $G$ band relates to vibrations in the $\mathrm{sp}^{2}$ hybrid carbon atoms in the graphitic rings. The degree of disorder in the crystal structure was determined by the intensity ratios of the D band and $\mathrm{G}$ band (ID/IG) [42,43]. Values of 1.20, 1.35, and 1.1 were obtained for PD600, PD800, and PD1000, respectively. These values indicate a high degree of disorder compared to the ID/IG of 0.03 for graphite [44], which was attributed to the activation with $\mathrm{KOH}$ due to defects in the graphite structure of the carbon [31]. PD1000, in comparison, exhibited lower ID/IG, indicating a higher degree of graphitization due to the high temperature employed [45]. Similar values of ID/IG were reported for Dictyphora (0.92) [4] and Shiitake (0.97) [46]. The Raman and XRD results suggest that the fungus-derived carbons featured amorphous and disordered structures, which are advantageous for obtaining a greater surface area, albeit with potentially diminished electrical conductivity due to defects in the structure of the carbon [47].

\subsection{Surface Group Analysis}

The XPS spectra of PD600, PD800, and PD1000 (Figure 8a-c) showed three characteristic peaks, corresponding, respectively, to $\mathrm{C} 1 \mathrm{~s}, \mathrm{~N} 1 \mathrm{~s}$, and O1s. Figure $8 \mathrm{~b}, \mathrm{e}, \mathrm{h}$ present the deconvolution of C1s in samples PD600, PD800, and PD1000, respectively. The C1s spectrum features four component peaks centered at 284.6, 285, $286.6 \pm 0.1$, and $288.7 \pm 0.2 \mathrm{eV}$, corresponding to $\mathrm{C}=\mathrm{C}$ (sp2), $\mathrm{C}-\mathrm{C}$ (sp3) in aromatic rings, $\mathrm{C}-\mathrm{O}$ (epoxy and alkoxy), and $\mathrm{C}=\mathrm{O}$ (carbonyl), respectively [2].
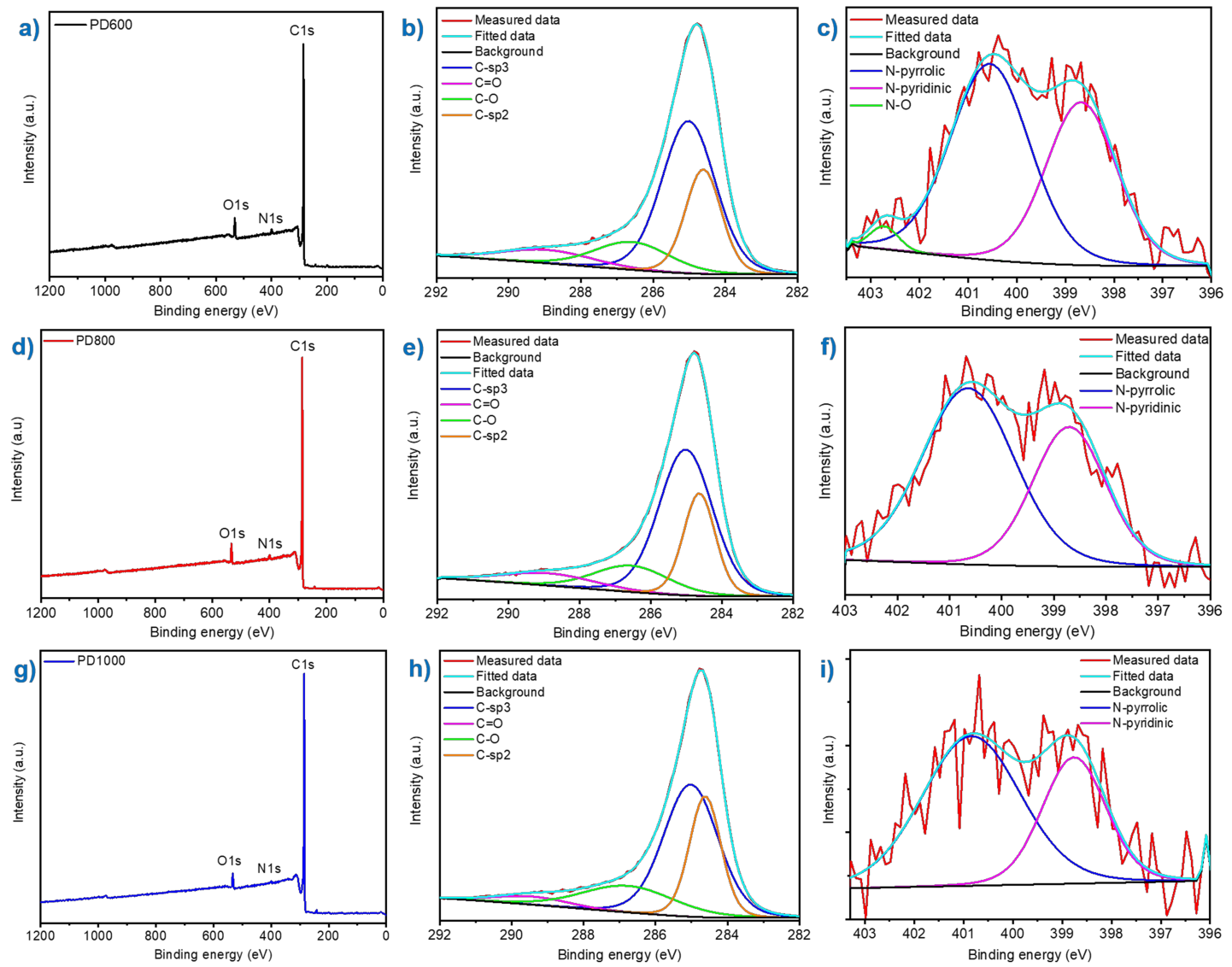

Figure 8. The XPS survey spectra of (a) PD600, (d) PD800, and (g) PD1000. High-resolution XPS spectra of the C1s peaks of (b) PD600, (e) PD800, and (h) PD1000. High resolution XPS spectra of N1s peaks (c) PD600, (f) PD800, and (i) PD1000. 
The N1s deconvolution of fungus-derived carbon is presented in Figure $8 \mathrm{c}, \mathrm{f}, \mathrm{i}$. For PD600, there were three peaks, which corresponded to $N$-pyridinic (398.7 eV), $N$-pyrrolic (400.6 eV), and N-O (402.72 eV). In PD800 and PD1000, two peaks were obtained at 398.7 and $400.7 \pm 0.1$, corresponding to $N$-pyridinic and $N$-pyrrolic, respectively $[34,39,48] . N$ pyridinic and $N$-pyrrolic can create extrinsic defects, such as more open channels and active sites for ion accumulation, which can improve material wettability and provide faradaic pseudocapacitance, thereby improving electrochemical performance $[42,43,48,49]$.

The elemental content of $\mathrm{C}, \mathrm{O}$, and $\mathrm{N}$ (Table 3) indicated that as temperatures increased, the content of the $\mathrm{N}$ and $\mathrm{O}$ heteroatoms decreased due to their instability at high temperatures, as the samples were composed mostly of elemental carbon, with some -O and $-\mathrm{N}$ functional groups on their surfaces [48]. The content of the functional groups in different carbons can contribute to pseudocapacitance characteristics, thereby helping to increase the total capacitance.

The content of $\mathrm{N}$ in the fungus-derived carbons was mainly composed of $N$-pyridinic and $N$-pyrrolic $N$, indicating defects in the carbon (Figure 9). $N$-pyridinic contributes one p electron to $\pi$ systems and binds two $C$ atoms in defects in graphene sheets, while $N$-pyrrolic contributes two electrons to the $\pi$ system [34]. There are no published reports of XPS on P. djamor in other investigations, however, there are few other fungi that have been studied using this technique, where the presence of $N$-pyridine and $N$-pyrrolic could also observed $[4,50]$. This result supports the results obtained by XRD, Raman, and TEM.

Table 3. Surface element atomic percentage (at $\%)$.

\begin{tabular}{|c|c|c|c|c|c|c|}
\hline \multirow{2}{*}{ Sample } & \multirow{2}{*}{$C_{X P S}$} & \multirow{2}{*}{$\mathbf{N}_{X P S}$} & \multirow{2}{*}{$\mathrm{O}_{\mathrm{XPS}}$} & \multicolumn{3}{|c|}{ Nitrogen Contents from XPS } \\
\hline & & & & Pyridinic $N$ & Pyrrolic $N$ & $\mathrm{~N}-\mathrm{O}$ \\
\hline PD600 & 93.16 & 1.55 & 5.29 & 41.37 & 56.29 & 2.35 \\
\hline PD800 & 93.31 & 1.63 & 5.06 & 38.48 & 61.52 & - \\
\hline PD1000 & 95.25 & 1.01 & 3.74 & 35.32 & 64.68 & - \\
\hline
\end{tabular}

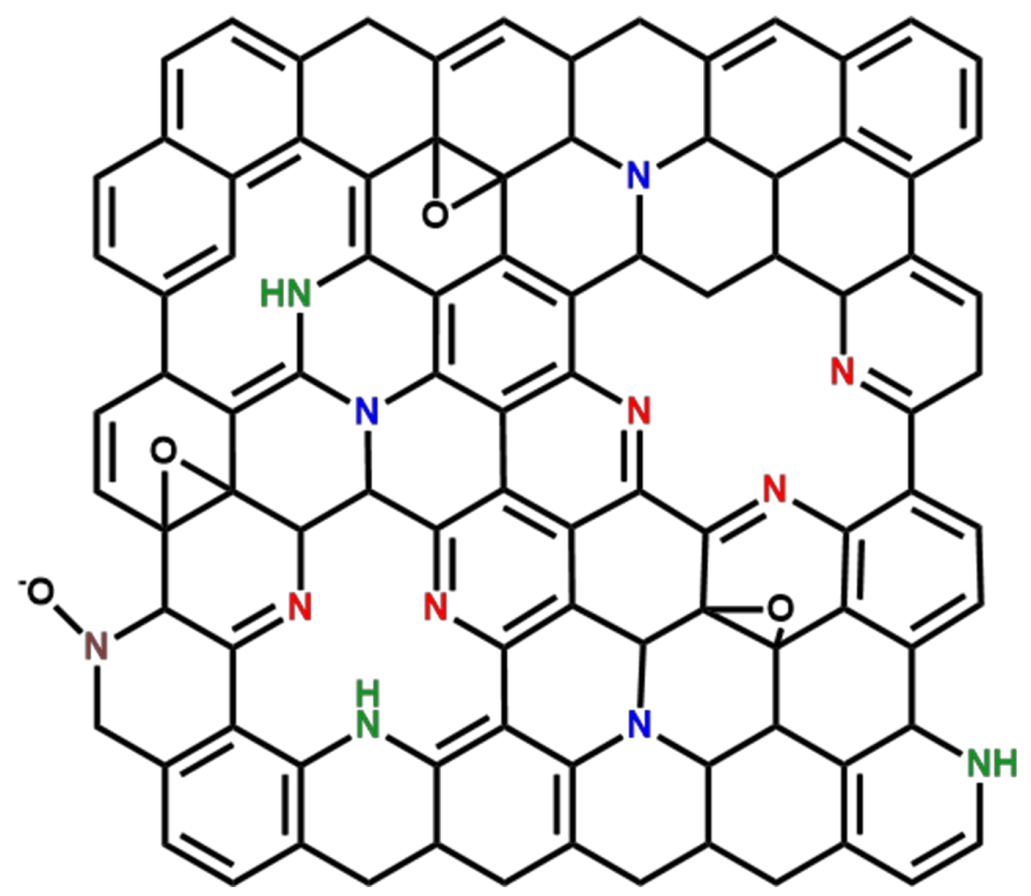

N - Quaternary N atom

N - Pyridinic $\mathbf{N}$ atom

N - Pyrrolic N atom

$\mathrm{N}$ - Pyridinic N-O atom

Figure 9. Schematic illustration of the bonding configuration for nitrogen atoms in the carbon lattice. 


\subsection{Electrochemical Behavior Tested in a Three-Electrode System}

The cyclic voltammetry plots of the fungus-derived carbons (Figure 10a) at a scan rate of $5 \mathrm{mVs}^{-1}$ showed a quasi-rectangular shape due to material resistance, suggesting a slight inclination and elongation of the tips of the curves. The specific capacitance was higher for all the materials obtained (Figure 10b), with a wider potential window recorded. Figure 10c shows a comparison of the variation in specific capacitance vs. the scan rate, all specific capacitances were calculated using Equation (4). PD1000 presented a greater drop in capacitance as the scan rate increased, possibly due to the nature of micropores, as indicated by the analysis of surface area. As the scan rate increased, the ions had less access to these pores in the material. The electrochemical performance of fungus-derived carbon varies depending on the precursor, activation process, and carbonization, because each of these factors modifies the morphology and chemical composition of the carbon obtained [5].

Table 4 shows the surface area and specific capacitance values from other studies which used biomass as feedstock. In all cases, the use of $6 \mathrm{M} \mathrm{KOH}$ was chosen due to its low cost, safety, and environmental friendliness. Furthermore, biomass-derived carbon tends to have functional groups, which interact directly with the electrolyte, causing protonation or deprotonation on the surface [51]. In the case of the $\mathrm{KOH}$ electrolyte, its surface is smoothed by the acidic O-groups into carboxylic groups during prolonged cycling; however, compared to other electrolytes, a more stable capacitance and cycling is obtained [51,52].
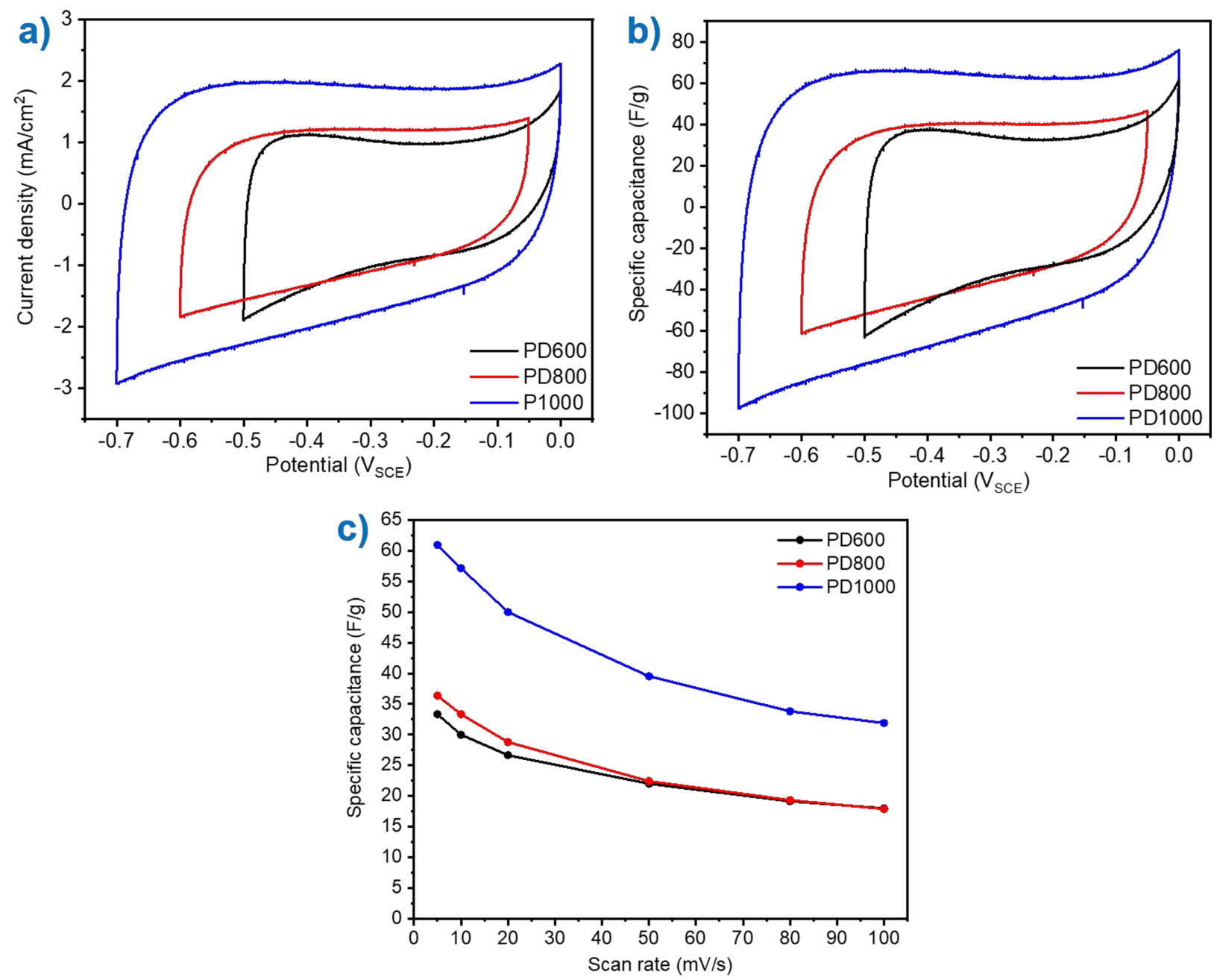

Figure 10. Electrochemical performance of PD600, PD800, and PD1000: (a) CV curves at $5 \mathrm{mVs}^{-1}$ in $6 \mathrm{M} \mathrm{KOH}$; (b) specific capacitance of fungus-derived carbon at $5 \mathrm{mVs}^{-1} ;$ (c) specific capacitance vs. scan rate. 
Table 4. Summary of the biomass-derived electrodes for supercapacitor applications.

\begin{tabular}{|c|c|c|c|c|c|c|c|}
\hline Feedstock & Process & $\begin{array}{c}\text { Activation } \\
\text { Agent }\end{array}$ & Pyrolysis & $\begin{array}{l}\text { Surface Area } \\
\qquad\left(\mathrm{m}^{2} \mathrm{~g}^{-1}\right)\end{array}$ & $\begin{array}{c}\text { Specific } \\
\text { Capacitance } \\
\left(F \mathrm{~g}^{-1}\right)\end{array}$ & Electrolyte & Ref. \\
\hline Chestnut shell & NA & $\mathrm{ZnCl}_{2}$ & $800{ }^{\circ} \mathrm{C}(1.5 \mathrm{~h})$ & 1987 & 92 & $6 \mathrm{M} \mathrm{KOH}$ & [53] \\
\hline Auricularia sp. & $\begin{array}{l}\text { Hydrothermal } \\
\text { carbonization }\end{array}$ & $\mathrm{N} / \mathrm{A}$ & $700{ }^{\circ} \mathrm{C}(3 \mathrm{~h})$ & 80 & 196 & $6 \mathrm{M} \mathrm{KOH}$ & [9] \\
\hline Auricularia sp. & $\begin{array}{l}\text { Hydrothermal } \\
\text { carbonization }\end{array}$ & $\mathrm{KOH}$ & $800^{\circ} \mathrm{C}(1 \mathrm{~h})$ & 1103 & 374 & $6 \mathrm{M} \mathrm{KOH}$ & [2] \\
\hline Dictyophora & Hydrothermal & $\mathrm{KOH}$ & $650{ }^{\circ} \mathrm{C}(2 \mathrm{~h})$ & $\mathrm{S} / \mathrm{I}$ & 310 & $6 \mathrm{M} \mathrm{KOH}$ & [4] \\
\hline Pleurotus djamor & Hydrothermal & $\mathrm{KOH}$ & $1000^{\circ} \mathrm{C}(2 \mathrm{~h})$ & 612.45 & 60 & $6 \mathrm{M} \mathrm{KOH}$ & This work \\
\hline
\end{tabular}

Regarding the electrochemical performance, the values obtained were lower than those reported in other studies; however, a competitive surface area with respect to what has already been researched was obtained, which was due to the porosity achieved by hydrothermal treatment.

The Nyquist plot in Figure 11a indicates similar behavior in all the derived carbons. These carbons presented almost vertical lines in the low frequency region due to a double layer capacitance. The equivalent circuit (Figure 11b) was obtained using the Zfit software (BioLogic); the obtained adjustment values are shown in Table 5. The equivalent circuit is composed of R1, R2, Q2, Q3, and W2. R1 refers to the equivalent series resistance, with the intersection of the semicircle representing the real axis. The diameters of the half circles represent the charge transport resistance (R2) across the electrode/electrolyte interface [31], in which the intrinsic resistance of the active material is involved. Q2 and Q3 are constant phase elements that represent the double-layer capacitive behavior and pseudocapacitance of the material. Warburg diffusion resistance (W2) was present in the medium frequency at an angle of $45^{\circ}$, including the resistance of ion diffusion and transport in the electrolyte $[43,54]$.

Table 5. Parameter values obtained from the EIS data fitting.

\begin{tabular}{|c|c|c|c|c|c|c|c|}
\hline Sample & $\begin{array}{c}\text { R1 } \\
\text { Ohm }\end{array}$ & $\begin{array}{c}\mathrm{R} 2 \\
\mathrm{Ohm}\end{array}$ & $\begin{array}{c}\mathrm{Q} 2 \\
\mathrm{~F} \bullet \mathrm{s}^{\wedge}(\mathrm{a}-1)\end{array}$ & a2 & $\begin{array}{c}\text { W2 } \\
\text { Ohm•^-1/2 }\end{array}$ & $\begin{array}{c}Q 3 \\
F^{\prime} s^{\wedge}(a-1)\end{array}$ & a3 \\
\hline PD600 & $0.68 \pm 0.6$ & $0.42 \pm 2.2$ & $1.95 \times 10^{-3} \pm 0.05$ & $0.77 \pm 1.0$ & $4.71 \pm 0.9$ & $0.2 \pm 0.07$ & $0.98 \pm 0.9$ \\
\hline PD800 & $0.78 \pm 1.0$ & $0.40 \pm 1.0$ & $1.46 \times 10^{-3} \pm 1$ & $0.79 \pm 0.8$ & $5.53 \pm 1.0$ & $0.32 \pm 1.0$ & $1.0 \pm 0.5$ \\
\hline PD1000 & $0.56 \pm 1.0$ & $0.16 \pm 1.0$ & $0.82 \times 10^{-3} \pm 1$ & $0.86 \pm 0.8$ & $3.39 \pm 1.0$ & $0.45 \pm 1.0$ & $1.0 \pm 0.5$ \\
\hline
\end{tabular}

Among the three fungus-derived carbons analyzed, PD1000 presented the lowest R1, R2, and W2 values, suggesting a fast ion-diffusion transfer rate and high electrical conductivity. The above result is consistent with the capacitance results obtained by CV. In addition, PD1000 exhibited a greater surface area than the other carbons.

The Bode plot (Figure $11 \mathrm{~b}-\mathrm{d}$ ) demonstrates that the impedance module and phase angle depended on frequency. In the electrodes, this capacitive behavior was observed between $90^{\circ}$ and $45^{\circ}$. Meanwhile, the resistance contributions and diffusion were between $0^{\circ}$ and $45^{\circ}$. PD600, PD800, and P1000 provided phase-angle values of $75^{\circ}, 73^{\circ}$, and $76^{\circ}$, respectively, in low-frequency regions. Failure to reach the ideal value of $90^{\circ}$ was mainly due to the presence of pseudocapacitive behavior [55]. 


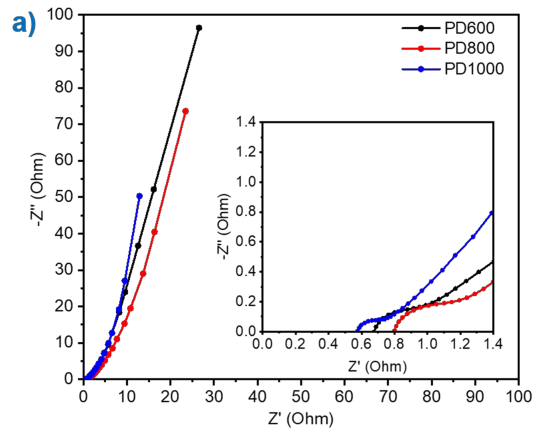

b)
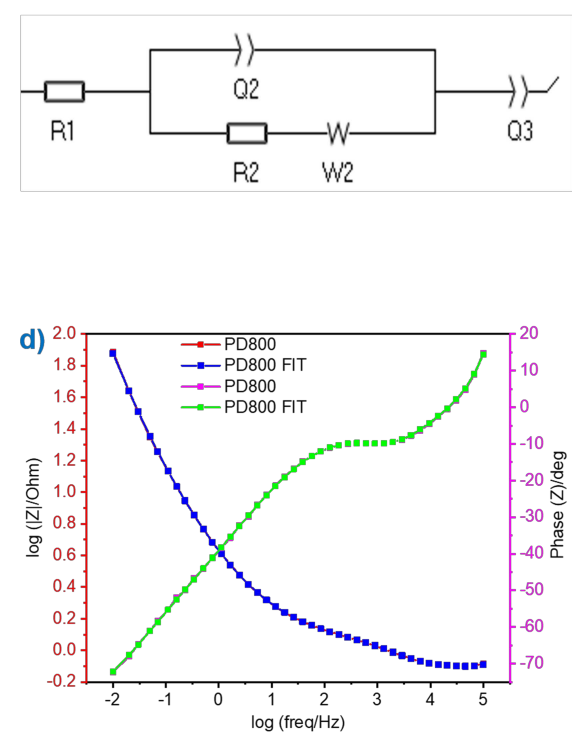

c)
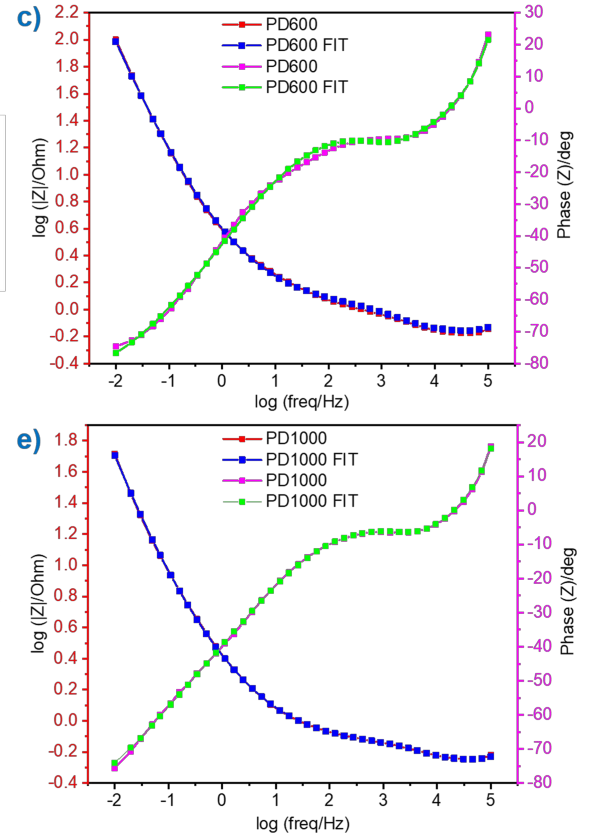

Figure 11. (a) Nyquist plot for the EIS spectra of PD600, PD800, and PD1000 (the small Z' region is shown in the inset); (b) the equivalent circuit used for fitting the experimental data; Bode plot of (c) PD600, (d) PD800, and (e) PD1000, including fitting.

\section{Conclusions}

In this study, fungus-derived hierarchical porous carbons were obtained through the use of agro-industrial waste as a substrate, and the subsequent treatment of the feedstock with a "green" hydrothermal activation methodology, which was then pyrolyzed at different temperatures. Firstly, using corn cobs as a substrate proved to be a viable option for the use of agricultural residues, helping to obtain added values of these. This may have been possible since the fungus studied, $P$. djamor, does not have as high nutritional requirements for the growing medium as other fungi studied for the same energy storage application, providing the opportunity to use other agro-industrial waste and thus contributing to the management of this waste. In addition, the methodology used for obtaining the fruit body of $P$. djamor is simple and does not require specialized equipment; they can be cultivated directly in the communities where these residues are produced, forming a value chain with a higher yield, and thus stimulating economic growth in the rural areas involved. Derived from the above, the carbon precursor used in the synthesis is economical, safe, and sustainable. Hydrothermal activation aided pore formation, which facilitated the development of structural defects during carbon pore formation. This was corroborated using SEM and TEM analyses, where the carbon's porous structure was found to possess a greater number of meso- and micropores. Due to the chemical composition observed in the FTIR of the feedstock, nitrogenous functional groups were observed in the fungus-derived carbons, which was corroborated by XPS, where $N$-pyrrolic and $N$-pyridinic were the most commonly observed varieties of N. PD1000 presented better characteristics than the 
other samples, with a greater specific surface area of $612.45 \mathrm{~m}^{2} \mathrm{~g}^{-1}$ and a greater specific capacitance of $61 \mathrm{Fg}^{-1}$ recorded. In summary, P. djamor biomass is suitable for obtaining materials with porous and ordered structures and surface areas that can compete against conventional carbons for use in high-performance electrochemical capacitors for sustainable energy storage technology. Another advantage of fungus-derived carbons is that feedstock offers shorter cultivation cycles and can employ any lignocellulosic residues. For future research, possible changes to the activation methodology and hydrothermal process could help preserve the hierarchical structure of the biomass. In this way, the surface area and specific capacitance could be increased without having to use temperatures as high as $1000{ }^{\circ} \mathrm{C}$, which can lead to degradation of the lignocellulose and proteins present in the fungus.

Author Contributions: Conceptualization, D.P.-C.; methodology, P.N.G.-H., T.T.-T. and J.M.B.-L.; software, P.N.G.-H., T.T.-T. and J.M.B.-L.; validation, P.N.G.-H., D.P.-C. and R.V.-O.; formal analysis, P.N.G.-H.; investigation, P.N.G.-H., D.P.-C. and R.V.-O.; resources, D.P.-C.; data curation, P.N.G.-H., J.M.B.-L. and T.T.-T.; writing-original draft preparation, P.N.G.-H.; writing-review and editing, D.P.-C. and R.V.-O.; visualization, D.P.-C. and P.N.G.-H.; supervision, D.P.-C. and R.V.-O.; project administration, D.P.-C.; funding acquisition, D.P.-C. All authors have read and agreed to the published version of the manuscript.

Funding: This research was funded by SENER-CONACYT Sust. Energética No. 254667, and a project and CONACYT student grant (486002) awarded to the first author.

Institutional Review Board Statement: Not applicable.

Informed Consent Statement: Not applicable.

Acknowledgments: The authors thank Wilian Cauich and Saúl García López for technical support. HRTEM analyses were performed at the Centro de Investigación en Ciencia y Tecnología Aplicada de Tabasco, UJAT-DAIA, (225962 project, CONACYT_INFRA 2014); and technical manager PhD. Laura Lorena Díaz Flores. XPS measurements were performed at LANNBIO Cinvestav Mérida, under support from projects FOMIX-Yucatán 2008-108160 CONACYT LAB-2009-01-123913, 292692, 294643, 188345, 204822, 292692, and 294643; and CONACYT infrastructure projects (254667 and 2266).

Conflicts of Interest: The authors declare no conflict of interest. The funders had no role in the design of the study; in the collection, analyses, or interpretation of data; in the writing of the manuscript, or in the decision to publish the results.

\section{References}

1. Mensah-Darkwa, K.; Zequine, C.; Kahol, P.K.; Gupta, R.K. Supercapacitor Energy Storage Device Using Biowastes: A Sustainable Approach to Green Energy. Sustainability 2019, 11, 414. [CrossRef]

2. Long, C.; Chen, X.; Jiang, L.; Zhi, L.; Fan, Z. Porous layer-stacking carbon derived from in-built template in biomass for high volumetric performance supercapacitors. Nano Energy 2015, 12, 141-151. [CrossRef]

3. Ojha, K.; Kumar, B.; Ganguli, A.K. Biomass derived graphene-like activated and non-activated porous carbon for advanced supercapacitors. J. Chem. Sci. 2017, 129, 397-404. [CrossRef]

4. Zheng, Y.; Lian, Y.; Wang, D.; Ban, C.; Zhao, J.; Zhang, H. 3D fungi carbon by less-alkali activation for supercapacitors. Vacuum 2020, 181, 109746. [CrossRef]

5. Thomas, P.; Lai, C.W.; Bin Johan, M.R. Recent developments in biomass-derived carbon as a potential sustainable material for super-capacitor-based energy storage and environmental applications. J. Anal. Appl. Pyrolysis 2019, 140, 54-85. [CrossRef]

6. Jin, H.; Wang, X.; Shen, Y.; Gu, Z. A high-performance carbon derived from corn stover via microwave and slow pyrolysis for supercapacitors. J. Anal. Appl. Pyrolysis 2014, 110, 18-23. [CrossRef]

7. Li, X.; Su, Z.; Liang, P.; Zhang, J. Construction of fungus waste-derived porous carbon as electrode materials for electrochemical supercapacitor. Biomass Convers. Biorefin. 2021. Available online: https://link.springer.com/article/10.1007\%2Fs13399-021-01612 -9 (accessed on 5 June 2021). [CrossRef]

8. Sadh, P.K.; Duhan, S.; Duhan, J.S. Agro-industrial wastes and their utilization using solid state fermentation: A review. Bioresour. Bioprocess. 2018, 5, 1. [CrossRef]

9. Zhu, H.; Wang, X.; Yang, F.; Yang, X. Promising Carbons for Supercapacitors Derived from Fungi. Adv. Mater. 2011, 23, 2745-2748. [CrossRef]

10. Zhu, Z.; Jiang, H.; Guo, S.; Cheng, Q.; Hu, Y.; Li, C. Dual Tuning of Biomass-Derived Hierarchical Carbon Nanostructures for Supercapacitors: The Role of Balanced Meso/Microporosity and Graphene. Sci. Rep. 2015, 5, 15936. [CrossRef] 
11. Salmones, D. Pleurotus djamor, un hongo con potencial aplicación biotecnológica para el neotrópico. Rev. Mex. Micol. 2017, 46, 73-85. [CrossRef]

12. Piña-Guzmán, A.B.; Nieto-Monteros, D.A.; Robles-Martínez, F. Utilización de residuos agrícolas y agroindustriales en el cultivo y producción del hongo comestible seta (Pleurotus spp.). Rev. Int. Contam. Ambient. 2016, 32, 11. [CrossRef]

13. Villers-Ruiz, L.; Trejo-Vázquez, I. Impacto del cambio climático en los bosques y áreas naturales protegias de México. Interciencia 1998, 23, 10-19.

14. Maniscalco, M.P.; Volpe, M.; Messineo, A. Hydrothermal Carbonization as a Valuable Tool for Energy and Environmental Applications: A Review. Energies 2020, 13, 4098. [CrossRef]

15. Jain, A.; Balasubramanian, R.; Srinivasan, M.P. Hydrothermal conversion of biomass waste to activated carbon with high porosity: A review. Chem. Eng. J. 2016, 283, 789-805. [CrossRef]

16. Mbarki, F.; Selmi, T.; Kesraoui, A.; Seffen, M.; Gadonneix, P.; Celzard, A.; Fierro, V. Hydrothermal pre-treatment, an efficient tool to improve activated carbon performances. Ind. Crop. Prod. 2019, 140, 111717. [CrossRef]

17. Antero, R.V.P.; Alves, A.C.F.; Ferreira Sales, P.d.T.; de Oliveira, S.B.; Ojala, S.A.; Brum, S.S. A new approach to obtain mesoporousactivated carbon via hydrothermal carbonization of Brazilian Cerrado biomass combined with physical activation for bisphenol-A removal. Chem. Eng. Commun. 2019, 206, 1498-1514. [CrossRef]

18. Guzmán, G.; Mata, G.; Soto Velazco, C. El Cultivo de Los Hongos Cometibles con Especial Atención a Especies Tropicales y Subtropicales en Esquilmos y Residuos Agro-Industriales; Instituto Politécnico Nacional: Veracruz, Mexico, 1993.

19. Shao, Y.; Guizani, C.; Grosseau, P.; Chaussy, D.; Beneventi, D. Biocarbons from microfibrillated cellulose/lignosulfonate precursors: A study of electrical conductivity development during slow pyrolysis. Carbon 2018, 129, 357-366. [CrossRef]

20. Serafin, J.; Baca, M.; Biegun, M.; Mijowska, E.; Kaleńczuk, R.J.; Sreńscek-Nazzal, J.; Michalkiewicz, B. Direct conversion of biomass to nanoporous activated biocarbons for high CO2 adsorption and supercapacitor applications. Appl. Surf. Sci. 2019, 497, 143722. [CrossRef]

21. Balachandran, M.; Ag, K. Study of Stacking Structure of Amorphous Carbon by X-Ray Diffraction Technique. Int. J. Electrochem. Sci. 2012, 7, 3127-3134.

22. Zequine, C.; Ranaweera, C.K.; Wang, Z.; Singh, S.; Tripathi, P.; Srivastava, O.N.; Gupta, B.K.; Ramasamy, K.; Kahol, P.K.; Dvornic, P.R.; et al. High Per formance and Flexible Supercapacitors based on Carbonized Bamboo Fibers for Wide Temperature Applications. Sci. Rep. 2016, 6, 31704. [CrossRef]

23. Raman, J.; Jang, K.-Y.; Oh, Y.-L.; Oh, M.; Im, J.-H.; Lakshmanan, H.; Sabaratnam, V. Cultivation and Nutritional Value of Prominent Pleurotus spp.: An Overview. Mycobiology 2021, 49, 1-14. [CrossRef]

24. Raman, J.; Lakshmanan, H.; Kab-yeul, J.; Sabaratnam, V.; Raaman, N. Cultivation of pink Oyster mushroom Pleurotus djamor var. roseus on various agro-residues by low cost technique. J. Mycopathol. Res. 2018, 56, 213-220.

25. Rumengan, I.; Suryanto, E.; Modaso, R.; Wullur, S.; Tallei, T.; Limbong, D. Structural Characteristics of Chitin y Chitosan Isolated from the Biomass of Cultivated Rotifer, Brachionus rotundiformis. Int. J. Fish. Aquat. Sci. 2014, 3, 12-18.

26. Hernández-Cocoletzi, H.; Aguila, E.; Flores Agustin, O.; Viveros Nava, E.L.; Ramos Cassellis, E. Obtención y caracterización de quitosano a partir de exoesqueletos de camarón. Superf. Vacío 2009, 22, 57-60.

27. Lin, X.-Q.; Yang, N.; Lü, Q.-F.; Liu, R. Self-Nitrogen-Doped Porous Biocarbon from Watermelon Rind: A High-Performance Supercapacitor Electrode and Its Improved Electrochemical Performance Using Redox Additive Electrolyte. Energy Technol. 2019, 7, 1800628. [CrossRef]

28. Bekiaris, G.; Tagkouli, D.; Koutrotsios, G.; Kalogeropoulos, N.; Zervakis, G.I. Pleurotus Mushrooms Content in Glucans and Ergosterol Assessed by ATR-FTIR Spectroscopy and Multivariate Analysis. Foods 2020, 9, 535. [CrossRef]

29. Qi, L.; Tang, X.; Wang, Z.; Peng, X. Pore characterization of different types of coal from coal and gas outburst disaster sites using low temperature nitrogen adsorption approach. Int. J. Min. Sci. Technol. 2017, 27, 371-377. [CrossRef]

30. Shu, Y.; Bai, Q.; Fu, G.; Xiong, Q.; Li, C.; Ding, H.; Shen, Y.; Uyama, H. Hierarchical porous carbons from polysaccharides carboxymethyl cellulose, bacterial cellulose, and citric acid for supercapacitor. Carbohydr. Polym. 2020, 227, 115346. [CrossRef]

31. Zou, Z.; Jiang, C. Hierarchical porous carbons derived from leftover rice for high performance supercapacitors. J. Alloys Compd. 2020, 815, 152280. [CrossRef]

32. Sun, K.; Yu, S.; Hu, Z.; Li, Z.; Lei, G.; Xiao, Q.; Ding, Y. Oxygen-containing hierarchically porous carbon materials derived from wild jujube pit for high-performance supercapacitor. Electrochim. Acta 2017, 231, 417-428. [CrossRef]

33. Wang, J.; Liu, Q. Fungi-derived hierarchically porous carbons for high-performance supercapacitors. RSC Adv. 2015, 5, 4396-4403 [CrossRef]

34. Wang, R.; Wang, P.; Yan, X.; Lang, J.; Peng, C.; Xue, Q. Promising Porous Carbon Derived from Celtuce Leaves with Outstanding Supercapacitance and CO2 Capture Performance. ACS Appl. Mater. Interfaces 2012, 4, 5800-5806. [CrossRef] [PubMed]

35. Bichat, M.P.; Raymundo-Piñero, E.; Béguin, F. High voltage supercapacitor built with seaweed carbons in neutral aqueous electrolyte. Carbon 2010, 48, 4351-4361. [CrossRef]

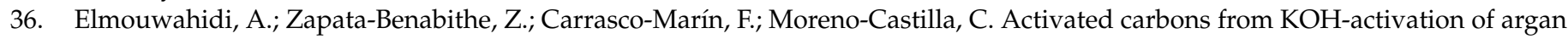
(Argania spinosa) seed shells as supercapacitor electrodes. Bioresour. Technol. 2012, 111, 185-190. [CrossRef]

37. Gannavarapu, K.P.; Azizighannad, S.; Molli, M.; Pandey, M.; Muthukumar, V.S.; Mitra, S.; Dandamudi, R.B. Nanoporous hierarchical carbon structures derived from fungal basidiocarps for high performance supercapacitors. Energy Storage 2019,1 , e58. [CrossRef] 
38. Liao, C.; Wu, C.; Yan, Y.; Huang, H. Chemical elemental characteristics of biomass fuels in China. Biomass Bioenergy 2004, 27, 119-130. [CrossRef]

39. Wang, L.; Zhu, Q.; Zhao, J.; Guan, Y.; Liu, J.; An, Z.; Xu, B. Nitrogen-doped hierarchical porous carbon for supercapacitors with high rate performance. Microporous Mesoporous Mater. 2019, 279, 439-445. [CrossRef]

40. Yuan, Y.; Yi, R.; Sun, Y.; Zeng, J.; Li, J.; Hu, J.; Zhao, Y.; Sun, W.; Zhao, C.; Yang, L.; et al. Porous Activated Carbons Derived from Pleurotus eryngii for Supercapacitor Applications. J. Nanomater. 2018, 2018, 1-10. [CrossRef]

41. Tang, J.; Etacheri, V.; Pol, V.G. Wild Fungus Derived Carbon Fibers and Hybrids as Anodes for Lithium-Ion Batteries. ACS Sustain. Chem. Eng. 2016, 4, 2624-2631. [CrossRef]

42. Huo, S.; Zhao, Y.; Zong, M.; Liang, B.; Zhang, X.; Khan, I.U.; Li, K. Enhanced supercapacitor and capacitive deionization boosted by constructing inherent $\mathrm{N}$ and $\mathrm{P}$ external defects in porous carbon framework with a hierarchical porosity. Electrochim. Acta 2020, 353, 136523. [CrossRef]

43. Wan, L.; Li, X.; Li, N.; Xie, M.; Du, C.; Zhang, Y.; Chen, J. Multi-heteroatom-doped hierarchical porous carbon derived from chestnut shell with superior performance in supercapacitors. J. Alloys Compd. 2019, 790, 760-771. [CrossRef]

44. Mori, F.; Kubouchi, M.; Arao, Y. Effect of graphite structures on the productivity and quality of few-layer graphene in liquid-phase exfoliation. J. Mater. Sci. 2018, 53, 12807-12815. [CrossRef]

45. Hu, J.; He, W.; Qiu, S.; Xu, W.; Mai, Y.; Guo, F. Nitrogen-doped hierarchical porous carbons prepared via freeze-drying assisted carbonization for high-performance supercapacitors. Appl. Surf. Sci. 2019, 496, 143643. [CrossRef]

46. Cheng, P.; Gao, S.; Zang, P.; Yang, X.; Bai, Y.; Xu, H.; Liu, Z.; Lei, Z. Hierarchically porous carbon by activation of shiitake mushroom for capacitive energy storage. Carbon 2015, 93, 315-324. [CrossRef]

47. Lu, H.; Zhao, X.S. Biomass-derived carbon electrode materials for supercapacitors. Sustain. Energy Fuels 2017, 1, 1265-1281. [CrossRef]

48. Wu, F.; Gao, J.; Zhai, X.; Xie, M.; Sun, Y.; Kang, H.; Tian, Q.; Qiu, H. Hierarchical porous carbon microrods derived from albizia flowers for high performance supercapacitors. Carbon 2019, 147, 242-251. [CrossRef]

49. Huang, G.; Geng, Q.; Kang, W.; Liu, Y.; Li, Y.; Xing, B.; Liu, Q.; Zhang, C. Hierarchical porous carbon with optimized mesopore structure and nitrogen doping for supercapacitor electrodes. Microporous Mesoporous Mater. 2019, 288, 109576. [CrossRef]

50. Guo, C.; Sun, L.; Liao, W.; Li, Z. The Use of an Edible Mushroom-Derived Renewable Carbon Material as a Highly Stable Electrocatalyst towards Four-Electron Oxygen Reduction. Materials 2016, 9, 1. [CrossRef]

51. Karamanova, B.; Stoyanova, A.; Shipochka, M.; Veleva, S.; Stoyanova, R. Effect of Alkaline-Basic Electrolytes on the Capacitance Performance of Biomass-Derived Carbonaceous Materials. Materials 2020, 13, 2941. [CrossRef]

52. Conder, J.; Fic, K.; Matei Ghimbeu, C. Supercapacitors (electrochemical capacitors). In Char and Carbon Materials Derived from Biomass. Production, Characterization and Applications; Mejdi, J., Lionel, L., Eds.; Elsevier: Amsterdam, The Netherlands, 2019; pp. 383-427. [CrossRef]

53. Cheng, L.; Guo, P.; Wang, R.; Ming, L.; Leng, F.; Li, H.; Zhao, X.S. Electrocapacitive properties of supercapacitors based on hierarchical porous carbons from chestnut shell. Colloids Surf. A Physicochem. Eng. Asp. 2014, 446, 127-133. [CrossRef]

54. Wan, L.; Wei, W.; Xie, M.; Zhang, Y.; Li, X.; Xiao, R.; Chen, J. Nitrogen, sulfur co-doped hierarchically porous carbon from rape pollen as high-performance supercapacitor electrode. Electrochim. Acta 2019, 311, 72-82. [CrossRef]

55. Raj, C.J.; Rajesh, M.; Manikandan, R.; Sim, J.Y.; Yu, K.H.; Park, S.Y.; Song, J.H.; Kim, B.C. Two-Dimensional Planar Supercapacitor Based on Zinc Oxide/Manganese Oxide Core/Shell Nano-architecture. Electrochim. Acta 2017, 247, 949-957. [CrossRef] 